Published in final edited form as:

J Allergy Clin Immunol Pract. 2017 ; 5(3): 744-749. doi:10.1016/j.jaip.2017.02.018.

\title{
Epidemiology and Incidence of ACE Inhibitor Angioedema Utilizing a Large Electronic Health Record
}

\author{
Aleena Banerji, MD ${ }^{1,2}$, Kimberly G. Blumenthal, MD ${ }^{1,2,3}$, Kenneth H. Lai, MA ${ }^{4}$, and Li Zhou, \\ MD, PhD $2,4,5$ \\ ${ }^{1}$ Division of Rheumatology, Allergy, and Immunology, Department of Medicine, Massachusetts \\ General Hospital, Boston, MA \\ ${ }^{2}$ Harvard Medical School, Boston, MA \\ ${ }^{3}$ Medical Practice Evaluation Center, Massachusetts General Hospital, Boston, Massachusetts \\ ${ }^{4}$ Partners HealthCare System, Boston, Massachusetts \\ ${ }^{5}$ Brigham and Women's Hospital, Boston, Massachusetts
}

\begin{abstract}
Background-Angiotensin-converting enzyme inhibitors (ACEI) are a common cause of druginduced angioedema in the United States. Most epidemiologic ACEI angioedema data are from large multi-center clinical trials.
\end{abstract}

Objective-Identify the incidence of and risk factors for ACEI angioedema using a large integrated electronic health record (EHR).

\begin{abstract}
Methods-We conducted a retrospective cohort study of all ACEI prescriptions in the outpatient setting of a large academic center between January 1, 2000 to September 30, 2008. We determined frequency, timing, and risk factors for ACEI angioedema within five years of prescription. All data were derived from EHR sources, with angioedema defined by EHR reactions of angioedema, swelling, edema, or lip, eye, face, tongue, throat or mouth swelling.
\end{abstract}

Results-Among 134,945 patients prescribed ACEI, 0.7\% ( $\mathrm{n}=888$ ) developed angioedema during the subsequent five years. Sex was similar but patients that developed ACEI angioedema were younger (61.5 vs. 62.7 years, $\mathrm{p}=0.007$ ). Patients with ACEI angioedema were more likely to have a history of NSAID allergy compared to patients that didn't develop angioedema ( $7.1 \% \mathrm{vs.}$ $4.2 \%, \mathrm{p}<0.001)$. We identified a $0.07 \%$ incidence of ACEI angioedema within one month of prescription and a $0.23 \%$ incidence during the first year. Incidence of angioedema was relatively constant annually over the subsequent four years $(0.10 \%-0.12 \%)$.

\footnotetext{
Corresponding author: Name: Aleena Banerji, MD, Address: Division of Rheumatology, Allergy, and Immunology, 55 Fruit Street, COX 201 Boston, MA 02114, Telephone number: 617-726-3850, Fax number: 617-724-0239, abanerji@ partners.org.

Publisher's Disclaimer: This is a PDF file of an unedited manuscript that has been accepted for publication. As a service to our customers we are providing this early version of the manuscript. The manuscript will undergo copyediting, typesetting, and review of the resulting proof before it is published in its final citable form. Please note that during the production process errors may be discovered which could affect the content, and all legal disclaimers that apply to the journal pertain.
} 
Conclusions-The incidence of ACEI angioedema within a large EHR is consistent with large clinical trial data. We observed a persistent and relatively constant annual risk; however, angioedema risk factors and underlying genetic and pathophysiological mechanisms require further study.

\section{Keywords}

angioedema; drug allergy; drug hypersensitivity; angiotensin converting enzyme; epidemiology; electronic health record

\section{INTRODUCTION}

Angiotensin converting enzyme inhibitors (ACEI) are the leading cause of drug-induced angioedema in the United States. Approximately $35 \%$ of all prescriptions written for antihypertensive medications in the United States are for ACEI and there are over 40 million patients taking these agents. ${ }^{1,2}$ It is estimated that there are over 100,000 emergency department visits for angioedema in the United States each year ${ }^{3}$ and ACEI angioedema accounts for $20-40 \%$ of these visits. ${ }^{4-6}$ ACEI associated angioedema is the most common cause of angioedema seen in the emergency department ${ }^{4}$ and a very frequent cause seen in our experience on the inpatient Allergy consult service. ${ }^{7}$ Understanding the epidemiology and risk factors for ACEI associated angioedema is important to managing any patient being prescribed an ACEI because it is associated with a high morbidity (intubation, intensive care unit admissions, and hospitalizations) and fatal reactions have been reported. ${ }^{8,9}$

Overall incidence of angioedema related to ACEI is reported in the literature to be between $0.1-0.7 \% .{ }^{2}, 10$ However, most of these epidemiologic data on ACEI associated angioedema are from multi-center clinical trials. While angioedema is described during the first week of exposure in over half of cases, it can occur any time during the course of therapy. ${ }^{11-13} \mathrm{~A}$ large retrospective study found that two-thirds of ACEI associated angioedema episodes occur within the first three months of therapy ${ }^{11}$ while case reports have documented angioedema episodes that began after years of stable therapy. ${ }^{14,15} \mathrm{~A}$ better understanding of when angioedema can occur from ACEI is needed to guide patient care.

We performed a retrospective study that aimed to estimate the timing and incidence of ACEI associated angioedema using a large, integrated EHR dataset.

\section{METHODS}

\section{Study Design and Population}

We conducted a large retrospective cohort study using the Partners HealthCare EHR to estimate the epidemiology and incidence of angioedema to ACEI. The study population included all patients prescribed at least one ACEI between January 1, 2000 and September 30, 2008 at any outpatient clinic associated with Partners HealthCare, an integrated health care system based in Boston, MA. Partners HealthCare is a large medical center that includes a referral population that is likely to be different from a rural healthcare setting. However, Partners provides medical care to more than a third of patients in the greater Boston area, in both tertiary care academic medical centers and community settings. 
Prescription data were obtained from the Longitudinal Medical Record (LMR), the outpatient EHR system used by providers affiliated with Partners HealthCare. Age, sex, and self-reported race were identified by EHR demographic tables. For patients prescribed multiple ACEI, the age at first prescription was used. Co-morbidities or indications for the use of an ACEI (coronary artery disease, hypertension, congestive heart failure, and proteinuria/nephrotic syndrome) were identified using problems recorded in the EHR "Problem List" within 30 days of ACEI prescription (before or after). Concomitant medications (antibiotics, opiates, aspirin and nonsteroidal anti-inflammatory drugs [NSAIDs]) were extracted from the EHR medication list. We defined a concomitant medication as any medication prescribed prior to: either the date of angioedema documentation, or within 5 years of ACEI prescription if angioedema did not occur. Similarly, we extracted drug allergies from the patient's allergy list, considering allergies entered prior to the development of ACEI associated angioedema, or within 5 years ofthe ACEI prescription.

The primary outcome was angioedema documented in the patient's allergy list in association with any previously prescribed ACEI. Angioedema was defined by any reported reaction of edema, angioedema, or any type of swelling, except, joint swelling, hand swelling, or fluid retention. Other immunologic and adverse reactions were similarly assessed, including cough, hyperkalemia, bronchospasm/wheezing, hives or other rash, renal toxicity, gastrointestinal upset, dizziness and headaches. For free-text entries (about 6\%), informatician investigators (KL, LZ) mapped free text to coded reactions using a semiautomated approach. Using a sample of entries, we manually created mappings between free-text and coded reactions. For example, the free-text reactions "angioedema," "angiodema," "face swelling," etc. were mapped to the coded reaction "Angioedema." All reaction forms manually mapped to angioedema were then identified in this dataset through automated searching and string matching.

We studied incidence of angioedema, analyzing the entire population and children (age 0-17 years old) separately. We assessed time to development of angioedema within the first five years after prescription of the ACEI.

\section{Statistical Analyses}

For frequency data, we report risk ratios (RR) with 95\% confidence intervals, while for continuous data, we report medians with inter-quartile ranges (IQR). We compared continuous data using the Wilcoxon Rank Sum test and compared frequencies using a chisquare test. Races were collapsed into binary variables for individual racial/ethnic comparisons. Statistical analysis was conducted using SAS version 9.4 (Cary, NC, USA). We use two-sided $\mathrm{p}$-values (with $\mathrm{p}<0.05$ being significant). This study was approved by the Partners Institutional Review Board. 


\section{RESULTS}

\section{Epidemiology of ACEI Associated Angioedema}

There were 134,945 patients prescribed an ACEI between January 1, 2000 to September 30, 2008. ACEI prescriptions included lisinopril (84.4\%), enalapril (5.7\%), quinapril (3.9\%), captopril (2.5\%), benazepril (2.3\%) and other generic ACEIs (5.5\%). Angioedema was identified in $0.7 \%(\mathrm{n}=888)$ patients during the subsequent five years. There were 288 children prescribed ACEI. None of these children developed ACEI angioedema during the subsequent five years. In children, the most frequently prescribed ACEI were enalapril (47.6\%), lisinopril (38.1\%), and captopril (13.0\%).

\section{Timing of ACEI Associated Angioedema}

Among 888 patients who developed ACEI associated angioedema, 10.2\% $(\mathrm{n}=91)$ developed angioedema within 30 days, including $4.3 \%(n=38)$ within 7 days, $6.8 \%(n=60)$ within 14 days, and $8.3 \%(\mathrm{n}=73)$ within 21 days. See Figure 1.

We identified a $0.07 \%$ incidence of ACEI angioedema within one month of initiation and a $0.23 \%$ incidence during the first year. Incidence of angioedema was relatively constant over the subsequent four years $(0.10 \%-0.12 \%)$.

\section{Patient Characteristics}

Patients who developed ACEI associated angioedema were slightly younger (61.5 vs. 62.7 years, $\mathrm{p}=0.007$ ) but sex was similar ( $48.9 \%$ vs. $51.1 \%$ male, $\mathrm{p}=0.21$ ) to patients that did not develop ACEI angioedema. See Table 1. Black (19.6\% vs. $5.9 \%, \mathrm{p}=<0.001)$ and Hispanic ( $6.8 \%$ vs. $5.1 \%, \mathrm{p}=0.03)$ race were significantly higher in patients who developed ACEI associated angioedema compared to patients who did not. All indications for ACEI prescriptions were not different between groups.

Patients with ACEI associated angioedema had a higher rate of a history of NSAID allergy (7.1\% vs. $4.2 \%, \mathrm{p}<0.001)$ and total number of drug allergies (median [IQR]: $1[1,2.5]$ vs. 0 $[0,1], \mathrm{p}<0.001)$, with less frequent concomitant NSAID use $(33.7 \%$ vs. $49.3 \%, \mathrm{p}<0.001)$ compared to patients that did not develop ACEI angioedema. Patients with NSAID allergy $(1.10 \%$ vs. $0.64 \%, \mathrm{p}<0.001)$ were more likely to develop ACEI angioedema than those without.

\section{ACEI Associated Reactions}

Cough was the most commonly reported reaction to ACEI (5.3\%), followed by angioedema $(0.7 \%)$, hyperkalemia $(0.4 \%)$ and bronchospasm/wheezing $(0.3 \%)$. See Table 2 . We identified a $0.5 \%$ incidence of cough and $0.04 \%$ incidence of bronchospasm/wheezing within one month of initiation. Among patients that developed ACEI associated cough, $10.1 \%$ developed symptoms within 1 month, $56.1 \%$ within 1 year, and $71.9 \%$ within 2 years. See Figure 1. Among patients that developed ACEI associated bronchospasm/wheezing, $12.3 \%$ developed symptoms within 1 month, $61.8 \%$ within 1 year, and $77.6 \%$ within 2 years. 


\section{DISCUSSION}

The incidence of ACEI associated angioedema within a large EHR is consistent with data from large clinical trials. Among 134,945 patients prescribed an ACEI, 0.7\% ( $\mathrm{n}=888)$ developed angioedema during the subsequent five years, similar to rates reported in the literature between 0.1 and $0.7 \%{ }^{2}, 10$ The literature suggests that the interval between onset of angioedema and initiation of ACEI treatment is generally days to weeks and occasionally years later. ${ }^{16}$ Prior reports describe $47-72 \%$ of patients with ACEI associated angioedema presenting within the first week of treatment. ${ }^{17}$ However, other more recent reports found that less than $25 \%$ of patients who develop angioedema showed symptoms within one month of starting ACEI therapy. ${ }^{13}$ Interestingly, we found that around $10 \%$ of patients who develop angioedema do so within the first month, but an annual rate that was similar every year after the first year of an ACEI prescription. These data support the recent literature and emphasize the importance of considering an ACEI as the cause of angioedema early into therapy, but also demonstrate that ACEI associated angioedema should be considered even after years of uneventful ACEI therapy.

Risk factors associated with ACEI associated angioedema have been reported in the literature, including Black race ${ }^{18,19}$ and female sex. ${ }^{20}$ Diabetes and obesity have been shown to increase severity of angioedema events. ${ }^{21}$ Our data did not show gender as a risk factor, but did suggest that patients who developed ACEI angioedema were more likely to be younger as well as Black or Hispanic. Hispanic race has been previously reported as a general risk factor for angioedema. ${ }^{22,23}$ Reasons for these findings are not clear but could relate to genetic polymorphisms. Three prior studies identified a gene region (XPNPEP2) associated with ACEI associated angioedema, ${ }^{23}$ but this was not specifically evaluated in large populations comparing different races. Data on the use of ACEI and frequency of ACEI-associated angioedema in the pediatric population are limited. In our study, we identified 288 children who were prescribed an ACEI. At an overall incidence of $0.7 \%$ over five years, we would have expected to see two children with ACEI associated angioedema but the number of children in our study is arguably small. Further study of risk factors and the underlying genetics and pathophysiology including in the pedatric population is still needed.

Patients who developed ACEI associated angioedema were more likely to have a history of an NSAID allergy and other drug allergy in our study. Similar findings have been reported by others ${ }^{24}$ and seen in our prior work implicating the addition of aspirin/NSAIDs or mast cell degranulators as contributing factors. ${ }^{7}$ However, the mechanisms for this remains unclear. NSAIDs can cause angioedema by either immunological (IgE-mediated) or nonimmunological reactions, where the latter are due to increased leukotriene production from inhibition of cyclooxygenase. ${ }^{25}$ It is also possible that the angioedema is mistakenly attributed to the ACEI in patients on both NSAIDs and ACEI or vice versa. Previous case reports have also implicated dental surgery, local anesthetics and interruption of ACEI therapy as possible triggers for angioedema but were not evaluated in this analysis and the pathophysiology was not been reported. ${ }^{26-31}$ Additionally, to our knowledge, there are no data to suggest differences between ACEI themselves, such as whether one ACEI is a higher risk for causing angioedema compared to another ACEI. However, this is certainly possible 
and would need to be studied further. It is clear that continued ACEI therapy after an episode of presumed ACEI associated angioedema is associated with much higher rates of recurrent angioedema compared to new ACEI users and patients who discontinue ACEI use. ${ }^{14,} 32$

Cough is a frequently reported side effect from ACEI that leads to discontinuation. While cough can develop within a few days to weeks after initiation, our study showed that patients frequently develop symptoms of cough after the first month of using an ACEI. This was similarly seen with other symptoms including bronchospasm/wheezing. These data have not been well described previously and are critically important to highlight to physicians prescribing ACEI and monitoring patients on ACEI therapy longer term. ACEI as a cause of cough and wheezing/bronchospasm, even without angioedema, should be considered even after years of uneventful ACEI therapy.

There were several limitations in our study. First, allergy data are not validated and could be patient-reported or clinician-observed. Also, ACEI angioedema is frequently a diagnosis of exclusion with no diagnostic testing available to confirm true allergy. Lab testing is a typical part of the clinical evaluation used to exclude other causes of angioedema. However, we did not ensure that labs were sent or other diagnoses were ruled out. There were 4 patients out of 888 who were prescribed another ACEI after their angioedema was reported and none developed angioedema subsequently. Additionally, retrospective EHR data were used and input of angioedema into the patient record could have occurred significantly later than the timing of the first angioedema episode. We evaluated risk factors in univariate analysis only; more comprehensive and adjusted analyses of risk factors for ACEI associated angioedema are needed. Lastly, data were obtained from a large academic medical center with a referral population that is likely to be different from a rural hospital or outpatient clinic setting.

The incidence of ACEI associated angioedema within a large EHR is consistent with large clinical trial data. We observed a persistent and relatively constant risk annually, which is important for physicians and patients to understand. Similarly, cough and other symptoms such as bronchspasm/wheezing associated with ACEI can occur even after the first few months of stable ACEI use. ACEI angioedema is a diagnosis made clinically and there are no laboratory studies that establish the diagnosis. Therefore, it is even more important to understand the risk factors for ACEI associated angioedema to decrease morbidity and improve care.

\title{
Acknowledgments
}

Funding: Funding: Dr. Li Zhou has R01 funding: AHRQ R01HS022728-01

\section{Abbreviations}

\author{
ACEI Angiotensin-converting enzyme inhibitors \\ EHR Electronic Health Record \\ LMR Longitudinal Medical Record \\ NSAIDs Nonsteroidal Anti-Inflammatory Drugs
}




$\begin{array}{ll}\text { RR } & \text { Risk Ratios } \\ \text { IQR } & \text { Inter-Quartile Range }\end{array}$

\section{References}

1. Ma J, Lee KV, Stafford RS. Changes in antihypertensive prescribing during US outpatient visits for uncomplicated hypertension between 1993 and 2004. Hypertension. 2006; 48:846-852. [PubMed: 16982967]

2. Messerli FH, Nussberger J. Vasopeptidase inhibition and angio-oedema. Lancet. 2000; 356:608609. [PubMed: 10968427]

3. Kelly M, Donnelly JP, McAnnally JR, Wang HE. National estimates of emergency department visits for angioedema and allergic reactions in the United States. Allergy Asthma Proc. 2013; 34:150-154. [PubMed: 23484890]

4. Banerji A, Clark S, Blanda M, LoVecchio F, Snyder B, Camargo CA Jr. Multicenter study of patients with angiotensin-converting enzyme inhibitor-induced angioedema who present to the emergency department. Ann Allergy Asthma Immunol. 2008; 100:327-332. [PubMed: 18450117]

5. Gabb GM, Ryan P, Wing LM, Hutchinson KA. Epidemiological study of angioedema and ACE inhibitors. Aust N Z J Med. 1996; 26:777-782. [PubMed: 9028507]

6. Sarkar P, Nicholson G, Hall G. Brief review: angiotensin converting enzyme inhibitors and angioedema: anesthetic implications. Can J Anaesth. 2006; 53:994-1003. [PubMed: 16987854]

7. Banerji A, Oren E, Hesterberg P, Hsu Y, Camargo CA Jr, Wong JT. Ten-year study of causes of moderate to severe angioedema seen by an inpatient allergy/immunology consult service. Allergy Asthma Proc. 2008; 29:88-92. [PubMed: 18302843]

8. Krizova A, Gardner T, Little DL, Arcieri-Piersanti V, Pollanen MS. Fatal laryngeal angioedema: a case report and a workup of angioedema in a forensic setting. Forensic Sci Med Pathol. 2015; 11:558-563. [PubMed: 26242774]

9. Ulmer JL, Garvey MJ. Fatal angioedema associated with lisinopril. Ann Pharmacother. 1992; 26:1245-1246. [PubMed: 1330096]

10. Quan M. Case study. ACE inhibitor-induced angioedema. Clin Cornerstone. 2009; 9(Suppl 3):S345. [PubMed: 19409355]

11. Toh S, Reichman ME, Houstoun M, et al. Comparative risk for angioedema associated with the use of drugs that target the renin-angiotensin-aldosterone system. Arch Intern Med. 2012; 172:15821589. [PubMed: 23147456]

12. Makani H, Messerli FH, Romero J, et al. Meta-analysis of randomized trials of angioedema as an adverse event of renin-angiotensin system inhibitors. Am J Cardiol. 2012; 110:383-391. [PubMed: 22521308]

13. Malde B, Regalado J, Greenberger PA. Investigation of angioedema associated with the use of angiotensin-converting enzyme inhibitors and angiotensin receptor blockers. Ann Allergy Asthma Immunol. 2007; 98:57-63. [PubMed: 17225721]

14. Brown NJ, Snowden M, Griffin MR. Recurrent angiotensin-converting enzyme inhibitorassociated angioedema. JAMA. 1997; 278:232-233. [PubMed: 9218671]

15. Beltrami L, Zanichelli A, Zingale L, Vacchini R, Carugo S, Cicardi M. Long-term follow-up of 111 patients with angiotensin-converting enzyme inhibitor-related angioedema. J Hypertens. 2011; 29:2273-2277. [PubMed: 21970934]

16. Slater EE, Merrill DD, Guess HA, et al. Clinical profile of angioedema associated with angiotensin converting-enzyme inhibition. JAMA. 1988; 260:967-970. [PubMed: 2840522]

17. Sabroe RA, Black AK. Angiotensin-converting enzyme (ACE) inhibitors and angio-oedema. Br J Dermatol. 1997; 136:153-158. [PubMed: 9068723]

18. Mahoney EJ, Devaiah AK. Angioedema and angiotensin-converting enzyme inhibitors: are demographics a risk? Otolaryngol Head Neck Surg. 2008; 139:105-108. [PubMed: 18585570]

J Allergy Clin Immunol Pract. Author manuscript; available in PMC 2018 May 01. 
19. Brown NJ, Ray WA, Snowden M, Griffin MR. Black americans have an increased rate of angiotensin converting enzyme inhibitor-associated angioedema. Clin Pharmacol Ther. 1996; 60:8-13. [PubMed: 8689816]

20. Campo P, Fernandez TD, Canto G, Mayorga C. Angioedema induced by angiotensin-converting enzyme inhibitors. Curr Opin Allergy Clin Immunol. 2013; 13:337-344. [PubMed: 23743513]

21. Stauber T, Confino-Cohen R, Goldberg A. Life-threatening angioedema induced by angiotensinconverting enzyme inhibitors: characteristics and risk factors. Am J Rhinol Allergy. 2014; 28:5458. [PubMed: 24717884]

22. Loftus PA, Tan M, Patel G, et al. Risk factors associated with severe and recurrent angioedema: an epidemic linked to ACE-inhibitors. Laryngoscope. 2014; 124:2502-2507. [PubMed: 24938823]

23. Mahmoudpour SH, Leusink M, van der Putten L, et al. Pharmacogenetics of ACE inhibitorinduced angioedema and cough: a systematic review and meta-analysis. Pharmacogenomics. 2013; 14:249-260. [PubMed: 23394388]

24. Kampitak T. Recurrent severe angioedema associated with imidapril and diclofenac. Allergol Int. 2008; 57:441-443. [PubMed: 18946239]

25. Kaplan AP, Greaves MW. Angioedema. J Am Acad Dermatol. 2005; 53:373-388. [PubMed: 16112343]

26. Ogbureke KU, Cruz C, Johnson JV, Helfrick JF. Perioperative angioedema in a patient on longterm angiotensin-converting enzyme (ACE)-inhibitor therapy. J Oral Maxillofac Surg. 1996; 54:917-920. [PubMed: 8676243]

27. Peacock ME, Brennan WA, Strong SL, Prior RF, O’Neal RB, Van Dyke TE. Angioedema as a complication in periodontal surgery: report of a case. J Periodontol. 1991; 62:643-645. [PubMed: 1770424]

28. Sadeghi N, Panje WR. Life-threatening perioperative angioedema related to angiotensin-converting enzyme inhibitor therapy. J Otolaryngol. 1999; 28:354-356. [PubMed: 10604167]

29. Schiller PI, Messmer SL, Haefeli WE, Schlienger RG, Bircher AJ. Angiotensin-converting enzyme inhibitor-induced angioedema: late onset, irregular course, and potential role of triggers. Allergy. 1997; 52:432-435. [PubMed: 9188926]

30. Seymour RA, Thomason JM, Nolan A. Angiotensin converting enzyme (ACE) inhibitors and their implications for the dental surgeon. Br Dent J. 1997; 183:214-218. [PubMed: 9345800]

31. Dyer PD. Late-onset angioedema after interruption of angiotensin converting enzyme inhibitor therapy. J Allergy Clin Immunol. 1994; 93:947-948. [PubMed: 8182239]

32. Mahmoudpour SH, Asselbergs FW, Terreehorst I, Souverein PC, de Boer A, Maitland-van der Zee AH. Continuation of angiotensin converting enzyme inhibitor therapy, in spite of occurrence of angioedema. Int J Cardiol. 2015; 201:644-645. [PubMed: 26340133] 


\section{Highlights box}

\section{What is already known about this topic?}

ACEI are associated with angioedema usually presenting with swelling of the face and/or tongue. Overall incidence of angioedema related to ACEI is between $0.1-0.7 \%$.

\section{What does this article add to our knowledge?}

The incidence of ACEI angioedema within a large EHR is consistent with large clinical trial data. We found a $0.07 \%$ incidence of ACEI angioedema within one month of initiation and observed a persistent and relatively constant risk annually.

\section{How does this study impact current management guidelines?}

ACEI are associated with angioedema, cough and bronchospasm/wheezing early in therapy, but our data suggeststhat ACEI should be considered causative of angioedema, cough and bronchospasm/wheezing even after years of uneventful therapy. 

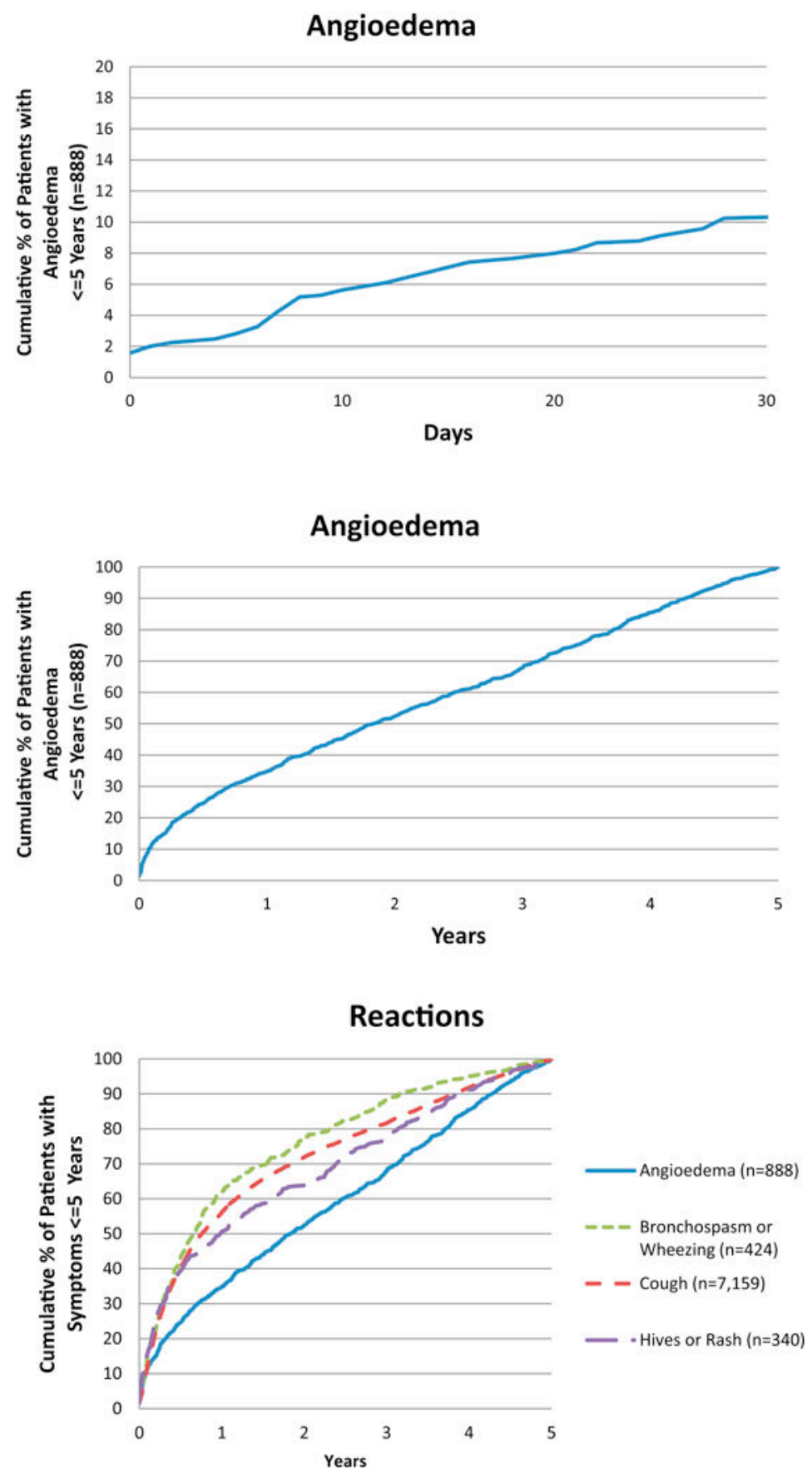

Figure 1.

Timing of reactions to ACE inhibitors documented in EHRs 
Table 1

Characteristics of Patients Prescribed ACEI from January 1, 2000 and September 30, $2008(n=134,945)$

\begin{tabular}{|c|c|c|c|}
\hline & $\begin{array}{c}\text { Angioedema } \\
(\mathbf{n}=\mathbf{8 8 8})\end{array}$ & $\begin{array}{c}\text { No Angioedema } \\
(\mathrm{n}=134,057)\end{array}$ & $P$ value \\
\hline \multicolumn{4}{|l|}{ Demographics } \\
\hline Age (Med, IQR) ${ }^{*}$ & $61.5[52.2-71.2]$ & $62.7[52.6-74.0]$ & 0.007 \\
\hline Male gender (n, \%) & $435(48.9)$ & $68,520(51.1)$ & 0.21 \\
\hline \multicolumn{4}{|l|}{ Race (n, \%) } \\
\hline Asian & $20(2.2)$ & $2,281(1.7)$ & 0.21 \\
\hline Black & $174(19.6)$ & $7,945(5.9)$ & $<0.001$ \\
\hline Hispanic & $60(6.8)$ & $6,888(5.1)$ & 0.03 \\
\hline White & $585(65.9)$ & $101,675(75.8)$ & $<0.001$ \\
\hline Other & $8(0.9)$ & $1,596(1.2)$ & 0.43 \\
\hline Unknown & $41(4.6)$ & $13,672(10.2)$ & $<0.001$ \\
\hline \multicolumn{4}{|l|}{ Comorbidities/Indication ${ }^{* *}$ (n, \%) } \\
\hline Coronary artery disease & $28(3.2)$ & $5,993(4.5)$ & 0.06 \\
\hline Hypertension & $240(27.0)$ & $39,403(29.4)$ & 0.12 \\
\hline Congestive heart failure & $5(0.6)$ & $1,787(1.3)$ & 0.053 \\
\hline Proteinuria/nephrotic syndrome & $3(0.3)$ & $436(0.3)$ & 0.95 \\
\hline Concomitant NSAID use ${ }^{\dagger}$ & $299(33.7)$ & $66,092(49.3)$ & $<0.001$ \\
\hline \multicolumn{4}{|l|}{ Other drug allergies reported (n, \%) } \\
\hline NSAID allergy $t^{t}$ & $63(7.1)$ & $5,663(4.2)$ & $<0.001$ \\
\hline Total number of drug allergies (Med, IQR) $)^{t}$ & $1[1,2.5]$ & $0[0,1]$ & $<0.001$ \\
\hline \multicolumn{4}{|l|}{ Specific drug listed as causative agent $(\mathrm{n}, \%)^{* * * *}$} \\
\hline Benazepril/Lotensin & $27(3.0)$ & $3,021(2.2)$ & 0.12 \\
\hline Captopril/Capoten & $12(1.4)$ & $3,335(2.5)$ & 0.03 \\
\hline Enalapril/Vasotec & $38(4.3)$ & $7,589(5.7)$ & 0.08 \\
\hline Fosinopril/Monopril & $5(0.6)$ & $1,263(0.9)$ & 0.25 \\
\hline Lisinopril/Prinivil/Zestril & $774(87.2)$ & $113,095(84.4)$ & 0.02 \\
\hline Moexipril/Univasc & $3(0.3)$ & $1,826(1.4)$ & 0.02 \\
\hline Perindopril/Aceon/Coversyl & $1(0.1)$ & $61(0.05)$ & 0.37 \\
\hline Quinapril/Accupril & $23(2.6)$ & $5,226(3.9)$ & 0.05 \\
\hline Ramipril/Altace & $10(1.1)$ & $2,800(2.1)$ & 0.05 \\
\hline Trandolapril/Mavik & $5(0.6)$ & $1,459(1.1)$ & 0.14 \\
\hline
\end{tabular}

Use age at time of first prescription

Problem list, within 30 days before or after prescription

***

More than one ACEI could have been associated with angioedema

${ }^{\dagger}$ Medication list specifies use of an NSAID prior to entry of angioedema as allergy, or within 5 years if no angioedema reported

J Allergy Clin Immunol Pract. Author manuscript; available in PMC 2018 May 01. 
$F^{t}$ Prior to entry of angioedema as allergy, or within 5 years if no angioedema reported 


\section{Table 2}

Frequency of Reported Reactions to ACE Inhibitors

\begin{tabular}{|l|c|}
\hline Reaction Reported to ACE inhibitor & $\begin{array}{c}\text { Number (\%) } \\
\text { (n=134,945) }\end{array}$ \\
\hline Cough & $7,159(5.3)$ \\
\hline Angioedema & $888(0.7)$ \\
\hline Hyperkalemia & $580(0.4)$ \\
\hline Bronchospasm or Wheezing & $424(0.3)$ \\
\hline Hives or Other Rash & $340(0.3)$ \\
\hline Renal Toxicity & $221(0.2)$ \\
\hline Gastrointestinal Upset & $152(0.1)$ \\
\hline Dizziness & $135(0.1)$ \\
\hline Headaches & $78(0.1)$ \\
\hline
\end{tabular}

